\title{
RECUPERAÇÃO DO GENITOR RECORRENTE EM MILHO UTILIZANDO RETROCRUZAMENTO ASSISTIDO POR MARCADORES MICROSSATÉLITES
}

\author{
ANTÔNIO GILSON GOMES MESQUITA ${ }^{1}$ CLÁUDIA TEIXEIRA GUIMARÃES², SIDNEY NETTO \\ PARENTONI ${ }^{2}$, EDILSON PAIVA $^{2}$
}

\author{
${ }^{1}$ Professor da Universidade Federal do Acre. Rio Branco, AC. \\ ${ }^{2}$ Pesquisadores da Embrapa Milho e Sorgo. Caixa Postal 151, CEP 35701-970, Sete Lagoas, MG. E-mail: \\ claudia@cnpms.embrapa.br (autor para correspondência)
}

Revista Brasileira de Milho e Sorgo, v.4, n.3, p.275-285, 2005

\begin{abstract}
RESUMO - Avaliou-se a utilização de marcadores microssatélites para acelerar a recuperação do genoma recorrente, em programas de retrocruzamento em milho. Uma linhagem com elevada capacidade geral de combinação para produtividade de grãos e alta inserção da espiga (L11) foi utilizada como genitor recorrente e uma linhagem com baixa inserção da espiga e baixa produtividade de grãos em cruzamento (L13) foi utilizada como genitor doador. A seleção fenotípica para baixa inserção de espiga foi realizada por dois ciclos de retrocruzamento e a recuperação do genoma do genitor recorrente nas plantas selecionadas foi monitorada utilizando-se marcadores SSR. Procurou-se, neste trabalho, comparar a recuperação do genoma recorrente em progênies de retrocruzamento selecionadas para baixa inserção da espiga, com e sem seleção assistida por marcadores. Para esse propósito, foi avaliada a produtividade de grãos dessas progênies em cruzamentos topcrosses, com uma linhagem testadora (L161), em três locais. Os resultados indicaram que os marcadores SSR foram eficientes na identificação de indivíduos com maior proporção de recuperação do genoma recorrente nos dois ciclos iniciais de retrocruzamento, permitindo um ganho de até três ciclos, se comparada com a recuperação esperada no retrocruzamento convencional. A seleção fenotípica para a baixa inserção da espiga foi eficiente, embora não tenha havido uma completa recuperação do fenótipo do genitor doador (L13), após dois ciclos de retrocruzamento. Foram obtidos híbridos topcrosses de progênies derivadas do retrocruzamento assistido mais produtivos e com inserção de espiga mais baixa que o híbrido topcross da linhagem recorrente. No entanto, as condições experimentais não permitiram concluir sobre a utilização da produtividade de grãos em híbridos topcrosses, na avaliação da recuperação do genoma recorrente, em programas de retrocruzamento em milho.
\end{abstract}

Palavras-chave: Zea mays, altura da espiga, topcross, SAM, SSR.

\section{RECOVERY OF RECURRENT GENOTYPE IN MAIZE USING SSR MARKER- ASSISTED BACKCROSS}

\begin{abstract}
This work was carried out to evaluate the use of microsatellite markers to accelerate the recovery of recurrent genome in maize backcross breeding programs. An inbred line with high general combining ability for grain yield and high ear insertion (L11) was used as recurrent parent, and a maize inbred line with low ear height and low grain yield in crosses (L3) was used as the donor parent. Phenotypic selection for low ear
\end{abstract}


insertion was performed in two backcross cycles, and the recover of the recurrent genotype of selected plants was monitored using SSR markers. The objective of this work was to compare the recovery of recurrent parent genotype in backcross progenies selected for low ear insertion, with and without marker-assisted selection. For this purpose, grain yield of these progenies were evaluated in topcross hybrids with a tester line (L161) in three locations. Results indicated that SSR markers were efficient in identifying individuals with a high proportion of the recurrent genome after the first two BC generations, allowing a gain of up to three generations compared to the theoretical recovery predicted in conventional backcross. Phenotypic selection for low ear insertion was efficient, although there was an incomplete recovery of the donor phenotype (L13) after two backcross generations. We obtained topcross hybrids from the progenies derived from markerassisted backcross showing higher yield and lower ear insertion than the recurrent topcross hybrid. However, our experimental conditions did not allow further conclusions about using the grain yield of topcross hybrids to evaluate the recovery of recurrent parent genome in backcross programs in maize.

Key words: Zea mays, ear height, topcross, MAS, SSR

O método do retrocruzamento tem por objetivo a introgressão de uma característica, normalmente mono ou oligogênica, de um genitor doador e a subseqüente recuperação do genoma do genitor recorrente. O processo geralmente é utilizado para corrigir genótipos-elites, nas características em que são deficientes, por meio do cruzamento com genótipos portadores das características que se deseja introduzir.

Uma das limitações do método é o longo tempo necessário para se completar o processo, fazendo com que o genótipo-elite utilizado como genitor recorrente muitas vezes se torne obsoleto, ao final do programa de retrocruzamento. Os marcadores moleculares apresentam-se como uma ferramenta importante para aumentar a eficiência desse processo, uma vez que possibilitam a identificação de indivíduos com maior proporção do genoma recorrente (Openshaw et al., 1994; Berloo, 1999; Hospital, 2001; Bouchez et al., 2002). A identificação da origem parental de cada região cromossômica, pela análise de dados moleculares, foi inicialmente proposta por Young \& Tanksley (1989), que sugeriram o conceito de genotipagem gráfica. Assim, é possível calcular a proporção de recuperação do genótipo recorrente, em cada indivíduo, na progênie de retrocruzamento, identificando-se aqueles que possuem menor proporção de alelos do genitor doador, em regiões do genoma que não aquela próxima ao gene-alvo (Frisch \& Melchinger, 2001). Dentre os tipos de marcadores moleculares disponíveis, os microssatélites (SSR) apresentamse como os mais adequados para a utilização nos programas de melhoramento, devido às suas características de co-dominância, multialelismo e possibilidade de automação (Beckman \& Soller, 1990; Ferreira \& Grattapaglia, 1998).

Nas espécies vegetais, os microssatélites são muito freqüentes e distribuídos ao acaso ao longo do genoma, sendo amplamente utilizados na construção de mapas genéticos (Taramino \& Tingey, 1996), no estudo da diversidade genética (Lu \& Bernardo, 2001), na caracterização de genótipos-elites (Padilha, 2002), na proteção de cultivares e na identificação de indivíduos com baixa porcentagem do genoma indesejável do genitor doador (Frisch et al., 1999). A utilização de marcadores moleculares em programas de retrocruzamento é considerada uma das aplicações 
mais concretas dessa tecnologia no melhoramento de plantas (Ferreira \& Grattapaglia, 1998). Programas de retrocruzamento assistido por marcadores moleculares podem ser usados para a transferência de genes ou de regiões cromossômicas que contenham alelos favoráveis e no desenvolvimento de linhagens semiisogênicas (Frisch \& Melchinger, 2001).

A altura da espiga é uma característica importante em programas de melhoramento de milho em que são selecionados genótipos com baixa inserção de espigas, para reduzir problemas de quebramento e facilitar a colheita mecânica. Entretanto, a correlação entre altura de espiga e produção é positiva (em torno de 0,3 ), o que dificulta a obtenção de híbridos produtivos e com baixa inserção de espiga. Segundo Hallauer \& Miranda Filho (1988), a herdabilidade média para altura de espiga é de $66,2 \%$, com predominância de efeitos aditivos, indicando condição favorável para seleção fenotípica. Por outro lado, a capacidade combinatória para a produtividade de grãos, que pode ser estimada por meio de cruzamentos com um testador comum (topcross), é um ponto chave na seleção de genótipos em um programa de melhoramento. Como essa característica é controlada por vários genes dispersos no genoma, seria esperado que, em retrocruzamentos utilizando um parental recorrente com alta capacidade combinatória para produtividade de grãos, as progênies com maior percentual de recuperação do genoma recorrente apresentassem maior produtividade de grãos em cruzamentos topcrosses.

O objetivo do presente trabalho foi avaliar a eficiência da utilização de marcadores microssatélites na recuperação do genoma recorrente, em programas de retrocruzamento em milho, utilizando a produtividade de grãos em topcrosses das progênies de retrocruzamento como característica indicadora.

\section{Material e Métodos}

\section{Obtenção e avaliação dos retrocruzamentos}

A linhagem L13 foi escolhida como genitor doador, por possuir baixa inserção de espiga, enquanto a linhagem L11 foi selecionada como genitor recorrente, por apresentar elevada capacidade geral de combinação para produtividade de grãos e alta inserção da espiga. As linhagens genitoras foram contrastantes para as características altura de espiga e produtividade de grãos, quando avaliadas em dialelo parcial envolvendo dez linhagens elite do programa de melhoramento da Embrapa Milho e Sorgo (Parentoni et al., 1996), sendo derivadas da população CMS14-C (Parentoni et al., 2001).

A geração $F_{1}$ e os ciclos de retrocruzamentos foram obtidos na Estação Experimental da Embrapa Milho e Sorgo, em Sete Lagoas, MG. Os campos de polinização foram conduzidos em fileiras de $5 \mathrm{~m}$, com espaçamento entre plantas de 0,20 m e de 0,90 m entre fileiras, com uma densidade de 20 plantas $/ \mathrm{m}$, sendo cada quatro fileiras intercaladas por uma do genitor recorrente (L11, masculino). $\mathrm{O}$ ciclo $\mathrm{RC}_{1} \mathrm{~F}_{1}$ foi constituído por 523 plantas e o $\mathrm{RC}_{2} \mathrm{~F}_{1}$, por 241 plantas.

As características fenotípicas avaliadas foram: altura da espiga (AE), altura da planta (AP), número de nós até a espiga (NNE) e número total de nós (NTN), sendo as três últimas utilizadas apenas como critério adicional para eliminação de plantas atípicas. Inicialmente, as gerações $\mathrm{RC}_{1} \mathrm{~F}_{1}$ e $\mathrm{RC}_{2} \mathrm{~F}_{1}$ foram selecionadas apenas quanto à baixa inserção de espiga, utilizando o critério de uma unidade de desvio padrão abaixo da média da população. As plantas selecionadas 
fenotipicamente foram genotipadas com marcadores SSR, sendo selecionadas para o próximo ciclo de retrocruzamento aquelas com pelo menos um desvio padrão acima da porcentagem média de recuperação do genoma recorrente. Para fins comparativos, o processo de retrocruzamento convencional, utilizando apenas a seleção fenotípica, e o retrocruzamento assistido por marcadores moleculares (seleção fenotípica e molecular) foram conduzidos em paralelo. O esquema de obtenção dos ciclos de retrocruzamento está descrito na Figura 1.

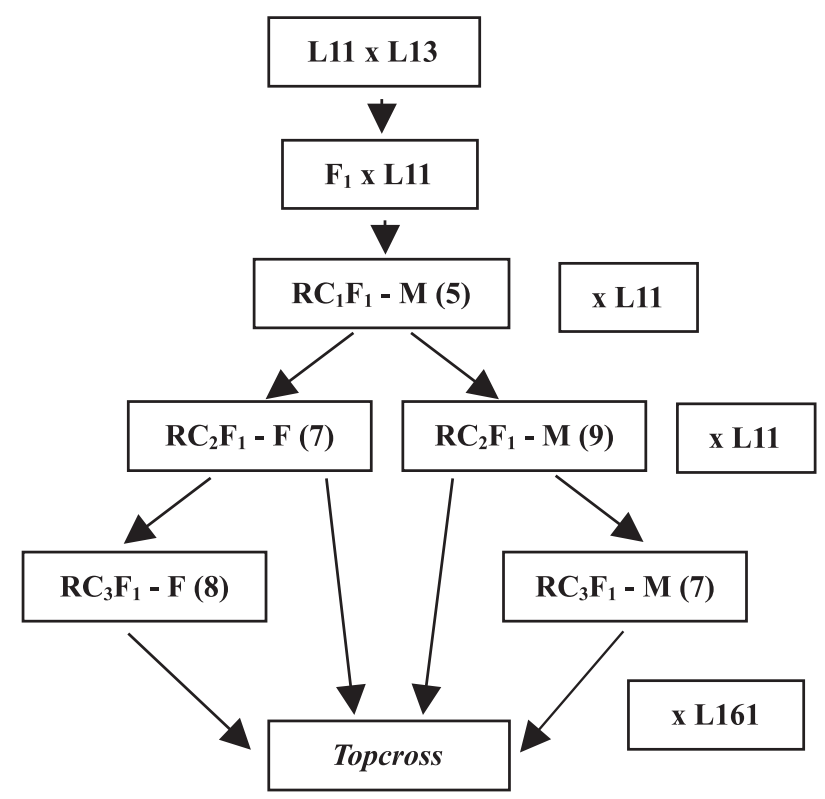

FIGURA 1. Esquema dos retrocruzamentos conduzidos até a obtenção do topcross. Os ciclos de retrocruzamento que foram selecionados apenas pelo fenótipo estão precedidos de F (RC - F) e aqueles cuja seleção foi realizada com base em dados fenotípicos e moleculares estão precedidos de M (RC - M). Os valores entre parênteses indicam o número de plantas selecionadas em cada geração.

\section{Marcadores SSR}

A extração do DNA e as reações de microssatélites foram realizadas segundo
Ninamango-Cárdenas et al. (2003), sendo os produtos de amplificação separados em gel de agarose $4 \%$, visualizados sob luz ultravioleta, em presença de brometo de etídio e fotodocumentados com o equipamento Eagle Eye II (Stratagene, La Jolla, CA).

Um total de 463 primers SSR foi avaliado entre as linhagens genitoras, para a identificação daqueles polimórficos. Para a análise dos indivíduos da geração $\mathrm{RC}_{1} \mathrm{~F}_{1}$, foram selecionados 27 primers polimórficos e, para a geração $\mathrm{RC}_{2} \mathrm{~F}_{1}$, foram avaliados 41 primers, totalizando 68 marcadores SSR distribuídos homogeneamente no genoma do milho, com uma média de 6,8 marcadores por cromossomo. Os primers em heterozigose nas plantas da geração $\mathrm{RC}_{1} \mathrm{~F}_{1}$ foram reavaliados nas suas progênies $\mathrm{RC}_{2} \mathrm{~F}_{1}$. Os dados moleculares foram codificados como A (alelo do genitor recorrente) ou $\mathrm{H}$ (heterozigoto) e analisados pelo programa Graphical Genotypes - GGT (Berloo, 1999).

\section{Obtenção e avaliação dos híbridos topcrosses}

As duas linhagens genitoras, sete plantas $\mathrm{RC}_{2} \mathrm{~F}_{1}-\mathrm{F}$, nove plantas $\mathrm{RC}_{2} \mathrm{~F}_{1}-\mathrm{M}$, oito plantas $\mathrm{RC}_{3} \mathrm{~F}_{1}-\mathrm{F}$ e sete plantas $\mathrm{RC}_{3} \mathrm{~F}_{1}-\mathrm{M}$, selecionadas conforme a Figura 1, foram cruzadas com uma linhagem testadora comum (L161). Os ciclos de retrocruzamento que foram selecionados apenas pelo fenótipo estão precedidos de F (RC-F) e aqueles cuja a seleção foi realizada com base em dados fenotípicos e moleculares estão precedidos de M (RC-M). Os 33 híbridos topcrosses foram avaliados em Goiânia, GO, Janaúba, MG e Sete Lagoas, MG, no ano agrícola de 2001/2002, utilizando-se o delineamento em blocos casualizados, com três repetições e uma testemunha intercalada a cada sete parcelas. A testemunha foi o híbrido simples comercial Pioneer P30F33, amplamente cultivado e de elevado 
desempenho agronômico. Cada parcela do experimento foi constituída por uma linha de $4 \mathrm{~m}$, com espaçamento de 0,90 m entre fileiras e de 0,20 m entre plantas, semeando-se 5 sementes/m linear, de forma a se obter uma densidade de 55.000 plantas/ha. Os tratos culturais foram realizados seguindo as recomendações técnicas para a cultura.

A altura da espiga (AE), em cm, foi avaliada em dez plantas representativas de cada parcela e a produtividade de grãos (PROD), em kg ha-1, foi ajustada, pela técnica de covariância, para o estande ideal de 20 plantas/parcelas, utilizando-se como co-variável o estande final, número total de plantas na parcela por ocasião da colheita (Cruz \& Carneiro, 2003). As análises de variância foram realizadas utilizando-se fatorial simples e fatorial com testemunha, para os desdobramentos dentro das progênies de retrocruzamento, por meio do programa Genes (Cruz, 2001).

\section{Resultados e Discussão}

\section{Seleção nos ciclos de retrocruzamento}

As 523 plantas $\mathrm{RC}_{1} \mathrm{~F}_{1}$ apresentaram distribuição normal para a característica altura de espigas, pelo teste de Shapiro-Wilk (5\%), com média de $122 \mathrm{~cm}$ e desvio padrão de $15 \mathrm{~cm}$. As
35 plantas selecionadas fenotipicamente apresentaram uma média de altura das espigas de $100 \pm$ $5 \mathrm{~cm}$, uma redução de $22 \mathrm{~cm}$ em relação à média da população original. Quando genotipadas com 27 pares de primers SSR, essas plantas geraram uma média de recuperação do genoma recorrente de 74,02 $\pm 5,92 \%$, em concordância com a média esperada na geração $\mathrm{RC}_{1} \mathrm{~F}_{1}$, que é de $75 \%$ $\left(\chi^{2}=0,051, p=0,82\right)$ (Figura 2A).

Segundo o critério de seleção genotípica utilizado, foram selecionadas cinco plantas $\mathrm{RC}_{1} \mathrm{~F}_{1}$ com média de recuperação do genótipo recorrente de $82,03 \%$, um avanço aproximado de $7 \%$ em relação ao retrocruzamento convencional. As cinco plantas selecionadas apresentaram a mesma média de altura de espiga das 35 plantas selecionadas fenotipicamente $(100 \mathrm{~cm})$, indicando que alelos responsáveis pela baixa AE foram mantidos nas plantas com maior recuperação do genótipo recorrente.

$\mathrm{Na}$ geração $\mathrm{RC}_{2} \mathrm{~F}_{1}, 241$ progênies foram obtidas a partir das cinco plantas selecionadas no $\mathrm{RC}_{1} \mathrm{~F}_{1}$, apresentando altura de espiga média de $83 \pm 10 \mathrm{~cm}$. Após a seleção fenotípica, foram selecionadas 31 plantas cuja média de AE foi de $70 \pm 6,0 \mathrm{~cm}$, que foram genotipadas com um total de 68 pares de primers SSR, distribuídos a
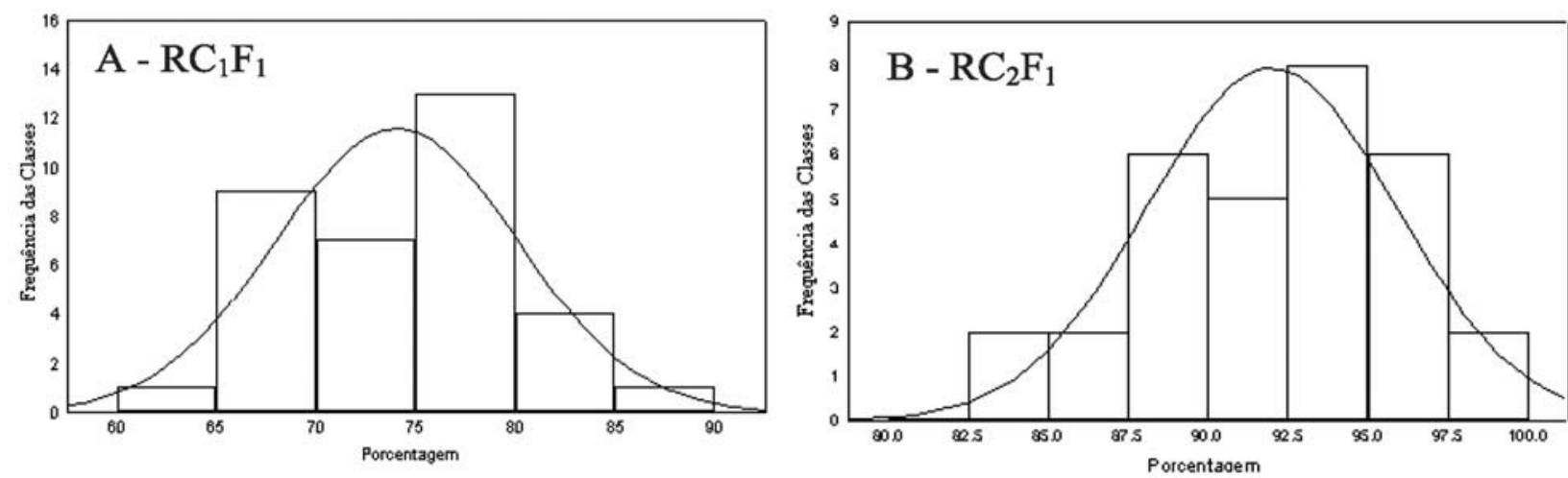

FIGURA 2. Porcentagem de recuperação do genoma recorrente, entre os 35 indivíduos $\mathrm{RC}_{1} \mathrm{~F}_{1}$ genotipados por SSR, com uma média de 74,02\% e distribuição normal, pelo teste de Shapiro-Wilk (W=0,9570) (A), e entre os 31 indivíduos $\mathrm{RC}_{2} \mathrm{~F}_{1}$ genotipados, com uma média de $91,98 \%$ e distribuição normal, pelo teste de Shapiro-Wilk (W=0,9570) $(\mathrm{B})$. 
uma distância média de 14 cM. Os ganhos obtidos com a seleção fenotípica na avaliação "per se" nos retrocruzamentos foram de 18,0 e 15,7\% no primeiro e segundo ciclos, respectivamente. Os indivíduos $\mathrm{RC}_{2} \mathrm{~F}_{1}$ genotipados apresentaram média de recuperação do genótipo recorrente de 91,98 $\pm 3,89 \%$, sendo que a média esperada seria de $87,5 \%\left(\chi^{2}=1,835, p=0,32\right)$ (Figura 2B).
Os sete indivíduos $\mathrm{RC}_{2} \mathrm{~F}_{1}$ selecionados apresentaram recuperação do genoma recorrente média de 96,44\%, valor que se aproxima da proporção de recuperação média teórica esperada em quatro ciclos de retrocruzamento, sendo que, em duas plantas, a proporção de recuperação foi de 98,20\%, o equivalente à média esperada no quinto ciclo de retrocruzamento. Na Figura 3, são apre-

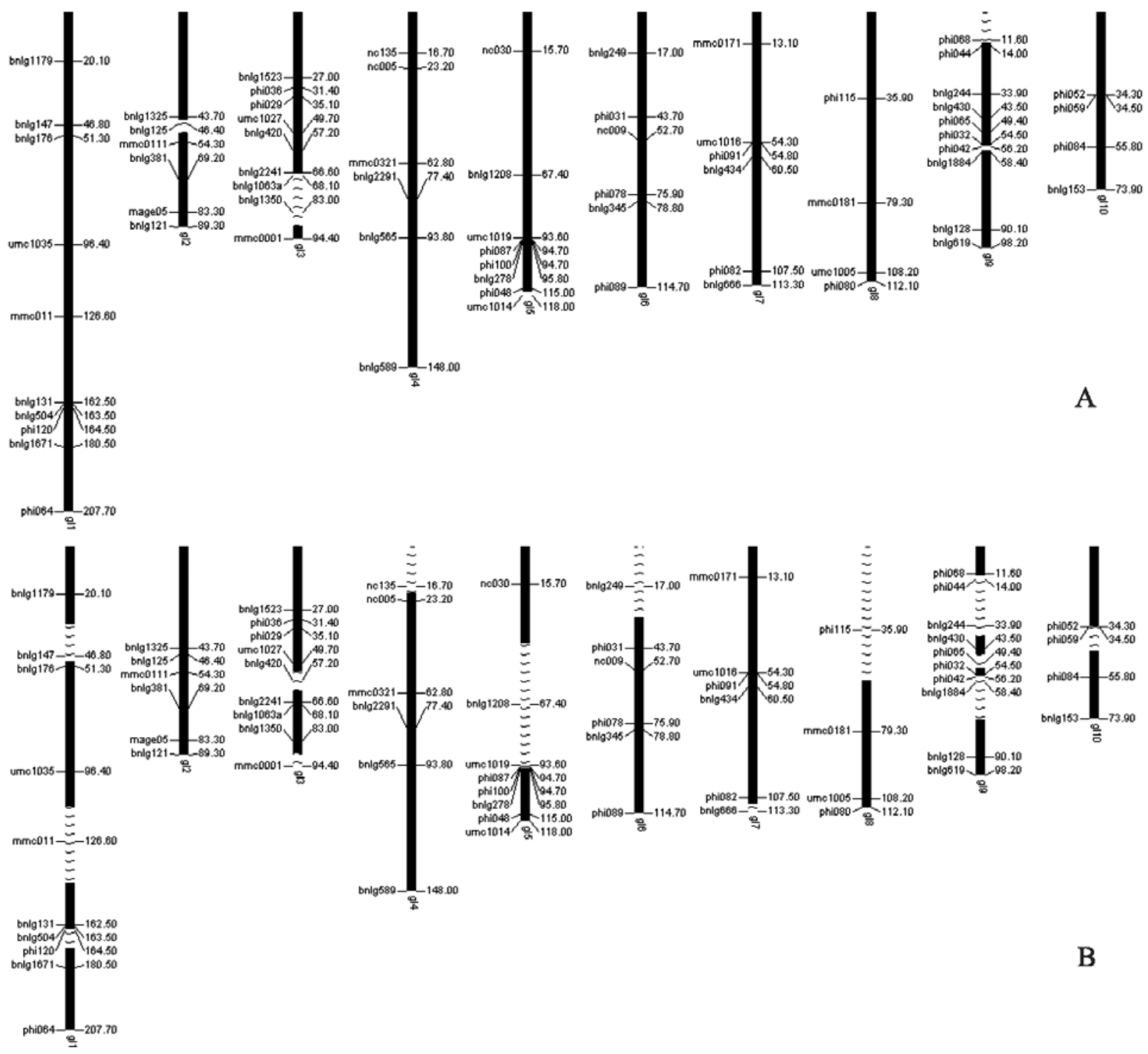

FIGURA 3. Genótipos gráficos das plantas $\mathrm{RC}_{2} \mathrm{~F}_{1}-31-156$ (A) e $\mathrm{RC}_{2} \mathrm{~F}_{1}-2-22$ (B), obtidas por retrocruzamento assistido, apresentando 98,2 e 87,65\% de recuperação do genoma recorrente, respectivamente. Os nomes dos marcadores estão indicados à esquerda e as respectivas posições em cM, à direita dos dez cromossomos de milho. Em preto estão representadas as porções do genoma recuperado e o tracejado representa as regiões em heterozigose. 
sentados os genótipos gráficos da planta $\mathrm{RC}_{2} \mathrm{~F}_{1}$ 31-156, com a máxima porcentagem de recuperação, de $98,2 \%$, do genoma recorrente obtida no segundo ciclo de retrocruzamento assistido e da planta $\mathrm{RC}_{2} \mathrm{~F}_{1}-2-22$, com $87,65 \%$, representando a média teórica esperada no mesmo ciclo de retrocruzamento convencional. Resultados semelhantes foram obtidos por Openshaw et al. (1994), Visscher et al. (1996) e Frisch et al. (1999), que conseguiram ganhos de uma a duas gerações de retrocruzamento, ao utilizarem marcadores SSR, espaçados de 10 a $20 \mathrm{cM}$, para selecionar progê- nies com grau elevado de recuperação do genoma recorrente.

\section{Avaliação da altura de espigas entre os híbridos topcrosses}

A avaliação da altura de espiga entre os 33 híbridos topcrosses apresentou diferença significativa nos três locais (dados não apresentados), após a análise de variância conjunta (Tabela 1). Quando os tratamentos foram desdobrados entre e dentro dos parentais e das progênies, não foram detectadas diferenças significativas entre os

TABELA 1. Resumo da análise de variância conjunta para as características altura de espiga (AE) em cm e produtividade de grãos (PROD), em $\mathrm{kg} \mathrm{ha}^{-1}$.

\begin{tabular}{|c|c|c|c|}
\hline \multirow{2}{*}{ F. V. } & \multirow{2}{*}{ G. L. } & \multicolumn{2}{|c|}{ QM } \\
\hline & & $\mathbf{A E}$ & PROD \\
\hline Rep/Local & 6 & $136,50^{\mathrm{ns}}$ & $7284320,81^{* *}$ \\
\hline Local (L) & 2 & $9197,60^{* *}$ & $13392944,14^{n s}$ \\
\hline Tratamento $(\mathrm{T})$ & 33 & $511,71^{* *}$ & $4488171,13^{* *}$ \\
\hline Entre os grupos & 3 & $1232,80^{* *}$ & $13404605,98^{* *}$ \\
\hline Entre os pais & 1 & $11350,22^{* *}$ & $2266114,70^{n}$ \\
\hline Dentro dos $\mathrm{RC}_{2} \mathrm{~F}_{1}$ & 15 & $63,25^{\mathrm{ns}}$ & 4543859,45 \\
\hline $\mathrm{RC}_{2} \mathrm{~F}_{1}-\mathrm{M}$ & 8 & $74,38^{\mathrm{ns}}$ & 5220475,95 \\
\hline $\mathrm{RC}_{2} \mathrm{~F}_{1}-\mathrm{F}$ & 6 & $34,38^{\mathrm{ns}}$ & $3619270,52^{n s}$ \\
\hline $\mathrm{RC}_{2} \mathrm{~F}_{1}-\mathrm{M} \times \mathrm{F}$ & 1 & $147,96^{\mathrm{ns}}$ & $4678461,22^{n}$ \\
\hline Dentro dos $\mathrm{RC}_{3} \mathrm{~F}_{1}$ & 14 & $63,53^{\mathrm{ns}}$ & $2676558,79^{n}$ \\
\hline $\mathrm{RC}_{3} \mathrm{~F}_{1}-\mathrm{M}$ & 6 & $53,09^{\mathrm{ns}}$ & $953489,14^{\mathrm{n}}$ \\
\hline $\mathrm{RC}_{3} \mathrm{~F}_{1}-\mathrm{F}$ & 7 & $81,49^{\mathrm{ns}}$ & $4470191,15^{\mathrm{ns}}$ \\
\hline $\mathrm{RC}_{3} \mathrm{~F}_{1}-\mathrm{M} \times \mathrm{F}$ & 1 & $0,38^{\mathrm{ns}}$ & $459550,03^{n}$ \\
\hline $\mathrm{L} \times \mathrm{T}$ & 66 & $53,75^{\mathrm{ns}}$ & $2694506,94^{\mathrm{n}}$ \\
\hline Resíduo & 198 & 46,72 & 2306356,57 \\
\hline CV (\%) & & 5,16 & 12,92 \\
\hline Média Geral & & 132,35 & 11756,29 \\
\hline $\begin{array}{l}\text { significativo a } 5 \% \text { de probabilid } \\
\text { * significativo a } 1 \% \text { de probabilid } \\
\text { não significativo. }\end{array}$ & $\begin{array}{l}\text { ste F. } \\
\text { ste } F \text {. }\end{array}$ & & \\
\hline
\end{tabular}


híbridos derivados das progênies $\mathrm{RC}_{2} \mathrm{~F}_{1}$ e $\mathrm{RC}_{3} \mathrm{~F}_{1}$, indicando uma transferência eficiente da característica já na geração inicial do retro-cruzamento. A variabilidade observada entre os tratamentos foi advinda das diferenças entre os híbridos topcrosses, envolvendo as linhagens parentais (Tabela 1). Tais resultados podem ser confirmados na Tabela 2, pela qual se nota que os híbridos derivados das linhagens genitoras situaram-se nos pontos extremos da distribuição. Os efeitos ambientais para AE foram significativos; entretanto, a interação tratamentos e ambiente não foi significativa, evidenciando que o comportamento dos híbridos para essa característica foi consistente nos diferentes ambientes avaliados.

Como a linhagem testadora L161 possui alta inserção de espigas, ela apresentou-se como boa testadora para avaliar a baixa inserção da espiga entre os híbridos, pelo fato de possuir uma baixa freqüência de alelos favoráveis para redução da altura das espigas. Apesar de ter havido uma redução substancial na altura de inserção das espigas, nos dois ciclos de retrocruzamento, não foi possível recuperar todos os alelos responsáveis pela redução da altura de espiga, uma vez que nenhum híbrido derivado das progênies $\mathrm{RC}_{2} \mathrm{~F}_{1}$ ou $\mathrm{RC}_{3} \mathrm{~F}_{1}$ foi agrupado junto com aquele derivado da linhagem doadora. Um dos fatores que pode ter contribuído para a recuperação incompleta da baixa altura de espiga foi a existência de locos em heterozigose para a característica do pai doador, tendo em vista que não foi realizado um ciclo final de autofecundação antes do cruzamento com a linhagem testadora.

\section{Avaliação da produtividade de grãos entre os híbridos topcrosses}

Para a produtividade de grãos, a variabilidade genética significativa detectada entre os tratamentos foi devido apenas às diferenças en- tre os híbridos derivados das progênies $\mathrm{RC}_{2} \mathrm{~F}_{1}$, selecionadas com base em dados moleculares (Tabela 1). Esse resultado pode ser confirmado pela Tabela 2, que evidencia a superioridade de dois híbridos derivados das progênies $\mathrm{RC}_{2} \mathrm{~F}_{1} 2 \mathrm{M}$ e $22 \mathrm{M}$, selecionadas por meio dos marcadores SSR, sugerindo uma maior eficiência na seleção realizada nos ciclos iniciais de retrocruzamento.

Apesar de as linhagens genitoras terem sido contrastantes para a produtividade de grãos, em cruzamentos dialélicos entre dez linhagens de milho (Parentoni et al., 1996), no presente trabalho, não houve diferença estatística pelo teste de Scott-Knott, a 5\% de probabilidade (Tabela 2). Esses resultados podem ter sido influenciados por variações ambientais, uma vez que a interação entre local e os híbridos formados pelas linhagens genitoras foi significativa, indicando que esses híbridos tiveram comportamento diferenciado nos ambientes avaliados (Tabela 1). Outra explicação pode estar na elevada capacidade geral de combinação da linhagem testadora (L161), para a característica em questão, conforme verificado por Parentoni et al. (2000) e ressaltado pelo fato de que $82 \%$ dos híbridos topcrosses avaliados foram superiores à testemunha, um híbrido simples de ampla aceitação comercial. A elevada frequiência de alelos favoráveis para a produtividade de grãos na linhagem testadora L161 pode ter mascarado os efeitos das contribuições genéticas das linhagens genitoras testadas.

Mesmo não tendo sido detectada diferença estatística para a produtividade de grãos, entre os híbridos derivados das linhagens genitoras, foram obtidos híbridos topcrosses de progênies $\mathrm{RC}_{2} \mathrm{~F}_{1}$ derivadas da seleção assistida superiores ao híbrido da linhagem recorrente L11 (Tabela 2). Destaque pode ser dado ao híbrido da progênie $\mathrm{RC}_{2} \mathrm{~F}_{1}-2 \mathrm{M}$, que foi o mais produtivo na media de três ambientes e apresentou altura da espi- 
TABELA 2. Agrupamento dos híbridos topcrosses utilizando média conjunta para as características altura de espiga (AE), em cm e produtividade de grãos (PROD), em kg ha ${ }^{-1}$, pelo teste de Scott-Knott, a 5\% de probabilidade.

\begin{tabular}{|c|c|c|c|}
\hline Híbridos topcrosses $^{1}$ & $\mathbf{A} \mathbf{E}^{2}$ & Híbridos topcrosses ${ }^{1}$ & PROD $^{2}$ \\
\hline L13 - pai doador & 111,38 a & P30F33 & $9.714,65 \mathrm{a}$ \\
\hline P30F33 & $113,34 \mathrm{a}$ & $\mathrm{RC}_{3} \mathrm{~F}_{1}-14-41 \mathrm{~F}$ & $10.406,23 \mathrm{a}$ \\
\hline $\mathrm{RC}_{2} \mathrm{~F}_{1}-44 \mathrm{M}$ & $128,72 \mathrm{~b}$ & $\mathrm{RC}_{2} \mathrm{~F}_{1}-64 \mathrm{~F}$ & $10.638,79 \mathrm{a}$ \\
\hline $\mathrm{RC}_{2} \mathrm{~F}_{1}-47 \mathrm{~F}$ & $129,11 \mathrm{~b}$ & $\mathrm{RC}_{2} \mathrm{~F}_{1}-54 \mathrm{M}$ & $10.813,58 \mathrm{a}$ \\
\hline $\mathrm{RC}_{3} \mathrm{~F}_{1}-59-317 \mathrm{~F}$ & $129,97 \mathrm{~b}$ & $\mathrm{RC}_{2} \mathrm{~F}_{1}-63 \mathrm{M}$ & $10.826,38 \mathrm{a}$ \\
\hline $\mathrm{RC}_{2} \mathrm{~F}_{1}-44 \mathrm{~F}$ & $130,27 \mathrm{~b}$ & $\mathrm{RC}_{2} \mathrm{~F}_{1}-67 \mathrm{~F}$ & $11.139,10 \mathrm{a}$ \\
\hline $\mathrm{RC}_{2} \mathrm{~F}_{1}-59 \mathrm{~F}$ & $130,33 \mathrm{~b}$ & $\mathrm{RC}_{2} \mathrm{~F}_{1}-45 \mathrm{~F}$ & $11.178,30 \mathrm{a}$ \\
\hline $\mathrm{RC}_{2} \mathrm{~F}_{1}-45 \mathrm{~F}$ & $130,50 \mathrm{~b}$ & $\mathrm{RC}_{3} \mathrm{~F}_{1}-51-279 \mathrm{~F}$ & $11.432,93 \mathrm{~b}$ \\
\hline $\mathrm{RC}_{2} \mathrm{~F}_{1}-2 \mathrm{M}$ & $130,58 \mathrm{~b}$ & $\mathrm{RC}_{2} \mathrm{~F}_{1}-59 \mathrm{~F}$ & $11.458,29 b$ \\
\hline $\mathrm{RC}_{2} \mathrm{~F}_{1}-67 \mathrm{~F}$ & $130,61 \mathrm{~b}$ & $\mathrm{RC}_{3} \mathrm{~F}_{1}-51-213 \mathrm{M}$ & $11.490,77 \mathrm{~b}$ \\
\hline $\mathrm{RC}_{2} \mathrm{~F}_{1}-64 \mathrm{~F}$ & $130,67 \mathrm{~b}$ & L13 & $11.611,66 \mathrm{~b}$ \\
\hline $\mathrm{RC}_{3} \mathrm{~F}_{1}-51-213 \mathrm{M}$ & $130,72 \mathrm{~b}$ & $\mathrm{RC}_{3} \mathrm{~F}_{1}-31-148 \mathrm{M}$ & $11.620,99 \mathrm{~b}$ \\
\hline $\mathrm{RC}_{3} \mathrm{~F}_{1}-54-292 \mathrm{~F}$ & $130,72 \mathrm{~b}$ & $\mathrm{RC}_{2} \mathrm{~F}_{1}-44 \mathrm{M}$ & $11.756,31 \mathrm{~b}$ \\
\hline $\mathrm{RC}_{3} \mathrm{~F}_{1}-31-170 \mathrm{M}$ & $130,88 \mathrm{~b}$ & $\mathrm{RC}_{3} \mathrm{~F}_{1}-28-153 \mathrm{~F}$ & $11.766,68 \mathrm{~b}$ \\
\hline $\mathrm{RC}_{2} \mathrm{~F}_{1}-54 \mathrm{M}$ & $131,09 \mathrm{~b}$ & $\mathrm{RC}_{2} \mathrm{~F}_{1}-18 \mathrm{M}$ & $11.769,42 \mathrm{~b}$ \\
\hline $\mathrm{RC}_{3} \mathrm{~F}_{1}-31-159 \mathrm{M}$ & $131,11 \mathrm{~b}$ & $\mathrm{RC}_{2} \mathrm{~F}_{1}-44 \mathrm{~F}$ & $11.777,29 \mathrm{~b}$ \\
\hline $\mathrm{RC}_{2} \mathrm{~F}_{1}-29 \mathrm{M}$ & $131,16 \mathrm{~b}$ & $\mathrm{RC}_{2} \mathrm{~F}_{1}-17 \mathrm{M}$ & $11.787,29 b$ \\
\hline $\mathrm{RC}_{3} \mathrm{~F}_{1}-14-41 \mathrm{~F}$ & $131,55 \mathrm{~b}$ & $\mathrm{RC}_{3} \mathrm{~F}_{1}-54-292 \mathrm{~F}$ & $11.845,82 \mathrm{~b}$ \\
\hline $\mathrm{RC}_{2} \mathrm{~F}_{1}-4 \mathrm{M}$ & $132,05 \mathrm{~b}$ & $\mathrm{RC}_{3} \mathrm{~F}_{1}-31-156 \mathrm{M}$ & $11.864,65 \mathrm{~b}$ \\
\hline $\mathrm{RC}_{3} \mathrm{~F}_{1}-67-378 \mathrm{~F}$ & $132,22 \mathrm{~b}$ & $\mathrm{RC}_{3} \mathrm{~F}_{1}-31-170 \mathrm{M}$ & $11.884,45 \mathrm{~b}$ \\
\hline $\mathrm{RC}_{3} \mathrm{~F}_{1}-28-153 \mathrm{~F}$ & $133,33 \mathrm{c}$ & $\mathrm{RC}_{3} \mathrm{~F}_{1}-3-13 \mathrm{~F}$ & $12.022,46 \mathrm{~b}$ \\
\hline $\mathrm{RC}_{3} \mathrm{~F}_{1}-31-150 \mathrm{M}$ & $133,38 \mathrm{c}$ & $\mathrm{RC}_{3} \mathrm{~F}_{1}-31-150 \mathrm{M}$ & $12.023,98 \mathrm{~b}$ \\
\hline $\mathrm{RC}_{3} \mathrm{~F}_{1}-3-13 \mathrm{~F}$ & $133,69 \mathrm{c}$ & $\mathrm{RC}_{3} \mathrm{~F}_{1}-67-378 \mathrm{~F}$ & $12.035,44 \mathrm{~b}$ \\
\hline $\mathrm{RC}_{3} \mathrm{~F}_{1}-31-148 \mathrm{M}$ & $134,77 \mathrm{c}$ & $\mathrm{RC}_{2} \mathrm{~F}_{1}-47 \mathrm{~F}$ & $12.096,38 \mathrm{~b}$ \\
\hline $\mathrm{RC}_{2} \mathrm{~F}_{1}-18 \mathrm{M}$ & $135,05 \mathrm{c}$ & $\mathrm{RC}_{2} \mathrm{~F}_{1}-4 \mathrm{M}$ & $12.173,53 \mathrm{~b}$ \\
\hline $\mathrm{RC}_{3} \mathrm{~F}_{1}-31-188 \mathrm{M}$ & $135,11 \mathrm{c}$ & $\mathrm{RC}_{3} \mathrm{~F}_{1}-59-317 \mathrm{~F}$ & $12.177,54 \mathrm{~b}$ \\
\hline $\mathrm{RC}_{2} \mathrm{~F}_{1}-77 \mathrm{~F}$ & $135,22 \mathrm{c}$ & $\mathrm{RC}_{2} \mathrm{~F}_{1}-29 \mathrm{M}$ & $12.189,09 \mathrm{~b}$ \\
\hline $\mathrm{RC}_{2} \mathrm{~F}_{1}-63 \mathrm{M}$ & $135,46 \mathrm{c}$ & $\mathrm{RC}_{3} \mathrm{~F}_{1}-31-188 \mathrm{M}$ & $12.314,94 \mathrm{~b}$ \\
\hline $\mathrm{RC}_{2} \mathrm{~F}_{1}-17 \mathrm{M}$ & $136,44 \mathrm{c}$ & L11 & $12.321,30 \mathrm{~b}$ \\
\hline $\mathrm{RC}_{2} \mathrm{~F}_{1}-22 \mathrm{M}$ & $136,45 \mathrm{c}$ & $\mathrm{RC}_{3} \mathrm{~F}_{1}-31-159 \mathrm{M}$ & $12.359,22 \mathrm{~b}$ \\
\hline $\mathrm{RC}_{3} \mathrm{~F}_{1}-51-279 \mathrm{~F}$ & $136,75 \mathrm{c}$ & $\mathrm{RC}_{2} \mathrm{~F}_{1}-77 \mathrm{~F}$ & $12.507,79 \mathrm{~b}$ \\
\hline $\mathrm{RC}_{3} \mathrm{~F}_{1}-31-156 \mathrm{M}$ & $136,86 \mathrm{c}$ & $\mathrm{RC}_{2} \mathrm{~F}_{1}-22 \mathrm{M}$ & $12.798,63 \mathrm{c}$ \\
\hline $\mathrm{RC}_{3} \mathrm{~F}_{1}-32-190 \mathrm{~F}$ & $138,72 \mathrm{c}$ & $\mathrm{RC}_{3} \mathrm{~F}_{1}-32-190 \mathrm{~F}$ & $12.873,32 \mathrm{c}$ \\
\hline L11 - pai recorrente & $161,61 \mathrm{~d}$ & $\mathrm{RC}_{2} \mathrm{~F}_{1}-2 \mathrm{M}$ & $13.036,39 \mathrm{c}$ \\
\hline Média Geral & 132,35 & Média Geral & 11756,28 \\
\hline
\end{tabular}

${ }^{1}$ F: Progênies do RC selecionadas apenas com base no fenótipo; M: Progênies do RC selecionadas com base no fenótipo e nos dados moleculares (RC assistido); linhagens parentais L13 e L11, cruzadas com o testador.

${ }^{2}$ Médias seguidas da mesma letra não diferiram significativamente, pelo teste de Scott-Knott, a 5\% de probabilidade 
ga $30 \mathrm{~cm}$ menor que o do parental recorrente (L11). Tais resultados, apesar de positivos, não permitem confirmar a hipótese testada no trabalho, de que uma maior recuperação do genoma recorrente implicaria maior recuperação da capacidade combinatória para produtividade de grãos nos híbridos topcrosses. Resultados semelhantes foram obtidos por Bouchez et al. (2002), que também não conseguiram uma introgressão de alelos favoráveis para produtividade de grãos satisfatória, utilizando retrocruzamento assistido, mesmo com uma eficiente recuperação do genoma recorrente. A complexidade genética da produtividade de grãos e a não utilização de marcadores moleculares flanqueando QTLs associados a essa característica podem ser apontados como fatores complicadores para a obtenção de resultados mais consistentes.

\section{Conclusões}

Os marcadores SSR foram eficientes na identificação de indivíduos com maior proporção de recuperação do genoma recorrente nas gerações iniciais de retrocruzamento, havendo um ganho de até três ciclos, se comparado com aquele esperado no retrocruzamento convencional.

A seleção fenotípica para a baixa inserção da espiga foi eficiente, embora todos os alelos não tenham sido recuperados nos dois ciclos de retrocruzamento. Foram obtidos híbridos topcrosses de progênies $\mathrm{RC}_{2} \mathrm{~F}_{1}$ derivadas da seleção assistida mais produtivos e com inserção de espiga mais baixa que o híbrido da linhagem recorrente. No entanto, as condições experimentais não possibilitaram concluir sobre a utilização da produtividade de grãos de híbridos topcrosses como característica para avaliar a recuperação do genoma recorrente, em programas de retrocruzamento convencional e assistido.

\section{Agradecimentos}

Os autores agradecem ao PRONEX/ CNPq e à Embrapa Milho e Sorgo o suporte técnico e financeiro, à Universidade Federal de Lavras e à CAPES a concessão da bolsa de estudo e à Universidade Federal do Acre a liberação e apoio concedidos.

\section{Literatura Citada}

BECKMAN, J. S.; SOLLER, M. Toward a unified approach to genetic mapping of eukaryotes based on sequence tagged microsatellite sites. Biotechnology, New York, v. 8, n. 10, p. 930-932, 1990.

BERLOO, R. van. GGT: software for the display of graphical genotypes. Journal of Heredity, Cary, v. 90, n. 2, p. 328-329, 1999.

BOUCHEZ, A.; HOSPITAL, F.; CAUSSE, M.; GALLAIS, A.; CHARCOSSET, A. Markerassisted introgression of favorable alleles at quantitative trait loci between maize elite lines. Genetics, Baltimore, n. 162, p. 1945-1959, 2002.

CRUZ, C. D. Programa Genes: versão Windows; aplicativo computacional em genética e estatística. Viçosa: UFV, 2001. 648 p.

CRUZ, C. D.; CARNEIRO, P. C. S. Modelos biométricos aplicados ao melhoramento genético. Viçosa: UFV, 2003. 585 p.

FERREIRA, M. E.; GRATTAPAGLIA, D. Introdução ao uso de marcadores moleculares em análise genética. 3. ed. Brasília, DF: EMBRAPA-CENARGEN, 1998. 220 p.

FRISCH, M.; BOLIN, M.; MELCHINGER, A. E. Minimum sample size and optimal positioning of flanking markers in marker-assisted backcrossing for transfer of a target gene. Crop Science, Madison, v. 39, n. 4, p. 967-975, 1999. 
FRISCH, M.; MELCHINGER, A. E. The length of the intact donor chromosome segment around a target gene in marker-assisted backcrossing. Genetics, Baltimore, v. 157, n. 3, p. 1343-1356, 2001.

HALLAUER, A. R.; MIRANDA FILHO, J. B. Quantitative genetics in maize breeding. 2. ed. Ames: Iowa State University Press, 1988. 468 p.

HOSPITAL, F. Size of donor chromosome segments around introgressed loci and reduction of linkage drag in marker-assisted backcross programs. Genetics, Baltimore, n. 158, p. 1363-1379, 2001.

LU, H.; BERNARDO, R. Molecular marker diversity among current and historical maize inbreds. Theoretical and Applied Genetics, Berlin, v. 103, n. 3, p. 613-617, Sept. 2001.

NINAMANGO-CÁRDENAS, F. E.; GUIMARÃES, C. T.; MARTINS, P. R.; PARENTONI, S. N.; CARNEIRO, N. P.; LOPES, M. A.; MORO, J. R.; PAIVA, E. Mapping QTLs for aluminum tolerance in maize. Euphytica, Dordrecht, v. 130, n. 2, p. 223-232, 2003.

OPENSHAW, S. J.; JARBOE, S. G.; BEAVIS, W. D. Marker assisted selection in backcross breeding. In: SYMPOSIUM ANALYSIS OF MOLECULAR MARKER DATA JOINT PLANT BREEDING SYMPOSIA SERIES, 1994, Corvallis. Proceedings... Corvallis: American Society for Horticultural Science: Crop Science of America, 1994. p. 41-43.

PADILHA, L. Marcadores moleculares semiautomatizados na caracterização e determinação da diversidade genética entre linhagens de milho tropical. 2002. 85 f. Tese (Doutorado) - Universidade Federal de Lavras, Lavras.

PARENTONI, S. N.; FRANÇA, G. E.; GAMA, E. E. G.; GUIMARÃES, P. E. O.; LOPES, M. A.; SANTOS, M. X. Eficiência na utilização de nitrogênio em linhagens de milho. In: CONGRESSO NACIONAL DE MILHO E SORGO, 1996, Londrina. Resumos... Londrina: IAPAR, 1996. p. 163.

PARENTONI, S. N.; MAGALHÃES, J. V.; PACHECO, C. A. P.; SANTOS, M. X.; ABADIE, T.; GAMA, E. E. G.; GUIMARÃES, P. E. O.; MEIRELES, W. F.; LOPES, M. A.; VASCONCELOS, M. J. V.; PAIVA, E. Heterotic groups based on yield-specific combining ability data and phylogenetic relationship determined by RAPD marker for 28 tropical maize open pollinated varieties. Euphytica, Dordrecht, v. 121, n. 2, p. 197-208, 2001.

PARENTONI, S. N.; VASCONCELOS, C. A.; ALVES, V. M. C.; PACHECO, C. A. P.; SANTOS, M. X.; GAMA, E. E. G.; MEIRELlES, W. F.; CORREA, L. A.; PITTA, G. V. E.; BAHIA FILHO, A. F. C. Eficiência na utilização de fósforo em genótipos de milho. In: CONGRESSO NACIONAL DE MILHO E SORGO, 23., 2000, Uberlândia. A inovação tecnológica e a competitividade no contexto dos mercados globalizados: resumos. Sete Lagoas: ABMS: Embrapa Milho e Sorgo: Universidade Federal de Uberlândia, 2000. p. 92

TARAMINO, G.; TINGEY, S. Simple sequence repeats for germplasm analysis and mapping in maize. Genome, Ottawa, v. 39, n. 2, p. 277-287, 1996.

VISSCHER, P. M.; HALEY, C. S.; THOMPSON, R. Marker-assisted introgression in backcross breeding program. Genetics, Baltimore, v. 144, n. 4, p. 1923-1932, 1996.

YOUNG, N. D.; TANKSLEY, S. D. Restriction fragment length polymorphisms maps and the concept of graphical genotypes. Theoretical and Applied Genetics, Berlin, v. 77, n. 1, p. 95-101, 1989. 